\title{
Growth and Characterization of L-Histidinium Ammonium Acetate Nonlinear Optical Single Crystal
}

\author{
T. Kavitha ${ }^{a, *}$, G. PAsupathi ${ }^{b}$, R. Gowri Shankar RaO ${ }^{c}$ And N. Kanagathara ${ }^{d}$ \\ ${ }^{a}$ Department of Physics, Idhaya College for Women, \\ Kumbakonam - 612 001, India \\ ${ }^{b} \mathrm{PG}$ and Research Department of Physics, AVVM Sri Pushpam College (Autonomous), \\ Poondi, Thanjavur - 613 503, Tamilnadu, India \\ ${ }^{c}$ School of Basic Sciences, Vel Tech University, Chennai - 600 062, India \\ ${ }^{d}$ Department of Physics, Saveetha School of Engineering, Saveetha Institute of Medical and Technical Sciences, \\ Thandalum, Chennai - 602 105, India
}

(Received July 20, 2018; revised version May 12, 2019; in final form August 7, 2019)

\begin{abstract}
A semi organic L-histidinium ammonium acetate (L-HAA) single crystal has been grown by slow evaporation technique. Single crystal X-ray diffraction studies confirm the monoclinic crystal system. Vibrational spectroscopic studies confirm the various functional groups present in the crystal. The ultraviolet-visible spectrum analysis has been carried out and the optical band energy gap for a grown crystal is calculated to be $5.5 \mathrm{eV}$ which indicates that the material is a good insulator and provides large transmission in visible region. Thermogravimetric-differential thermal analysis reveals that the material is thermally stable up to $273.02^{\circ} \mathrm{C}$. The second harmonic generation efficiency of L-HAA crystal is found to be 0.68 times lesser than that of KDP.
\end{abstract}

DOI: 10.12693/APhysPolA.136.395

PACS/topics: XRD, TG-DTA, SHG

\section{Introduction}

Nowadays nonlinear optical materials are having potential applications in the area of telecommunications and optical storage devices. Especially those materials, which can generate highly efficient second harmonic blue violet light by using laser diodes, are of great interest for wide variety of applications such as high-density data storage, under water communication, and medical diagnostics $[1,2]$. Amino acids and their complexes belong to a family of organic materials that have enormous applications in the field of nonlinear optics (NLO). Amino acids are interesting materials for NLO applications as they contain a proton donor carboxyl acid COO- group and the proton acceptor amino $\mathrm{NH}^{3+}$ group. Amino acids such as L-histidine, L-alanine, and L-arginine, have shown promising results as efficient second harmonic generators and are being applied in devices such as optical parametric amplifiers.

In the present study, we have synthesized the L-HAA by conventional chemical reaction and then the single crystal has been grown by slow evaporation solution growth technique. The grown single crystal has been analyzed by different characterization studies like X-ray diffraction, vibrational, optical, thermal, and second harmonic generation.

\section{Experimental procedure}

*corresponding author; e-mail: thangarajkavitha3@gmail.com

\subsection{Synthesis and crystal growth}

The calculated amounts of the analytical reagent (AR) grade starting materials of L-HAA were taken in equal molar ratio and dissolved in double distilled water. The mixture was thoroughly stirred for about $5 \mathrm{~h}$ using a magnetic stirrer to ensure homogeneous concentration throughout the volume of the solution. The chemical reaction is given below

$$
\mathrm{C}_{6} \mathrm{H}_{7} \mathrm{NO}_{2}+\mathrm{C}_{2} \mathrm{H}_{7} \mathrm{NO}_{2} \rightarrow \mathrm{NH}_{4}^{+}+\left[\mathrm{C}_{6} \mathrm{H}_{7} \mathrm{NO}_{2}\right] \mathrm{CH}_{3} \mathrm{COO}^{-}
$$

The saturated solution was filtered using the Whatmann filter paper. The filtered solution was taken in a beaker and covered with good quality perforated polythene cover to restrict the fast evaporation. Then the solution was kept at room temperature in a dust free compartment for slow evaporation. After the period of 28 days, colorless and optically transparent crystals of L-HAA with dimension $13 \times 8 \times 3 \mathrm{~mm}^{3}$ were obtained. The grown crystal is shown in Fig. 1.

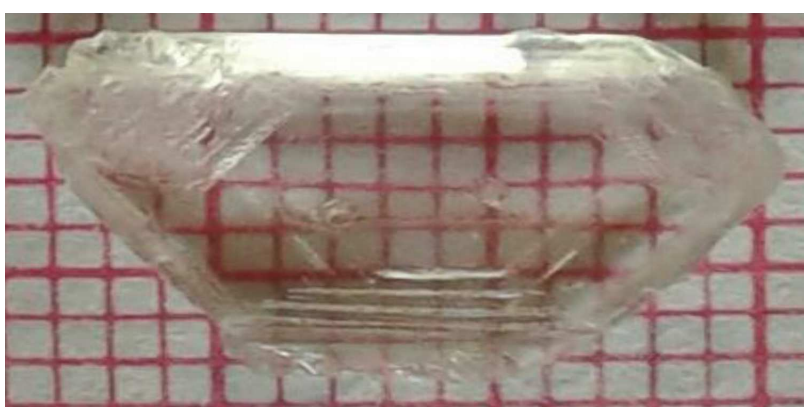

Fig. 1. Photograph of as grown LHAA crystal. 


\section{Results and discussion}

\subsection{Single crystal X-ray diffraction analysis}

The grown crystal of L-HAA were subjected to single crystal X-ray diffraction studies using an ENRAF NONIUS CAD4-Fdiffractometer with Mo $K_{\alpha}$ radiation $(\lambda=0.71073 \AA)$ to determine the crystal structure. Single crystal X-ray diffraction analysis reveals that the crystal belongs to monoclinic system with space group of $P 2{ }_{1} 2{ }_{1} 2_{1}$. The cell parameters of LHAA are calculated to be $a=5.22 \AA, b=7.47 \AA, c=9.55 \AA, \alpha=90^{\circ}$, $\beta=98.18^{\circ}, \gamma=90^{\circ}$, and $V=368 \AA^{3}$.

\subsection{Powder X-ray diffraction analysis}

Powder X-ray diffraction analysis of grown crystal has been carried out by using Bruker D8-Advance powder X-ray diffractometer with $\mathrm{Cu} K_{\alpha}(\lambda=1.5418 \AA)$ line radiation, in the range of scanning angle from $10^{\circ}$ to $80^{\circ}$ of 2 theta. The recorded powder X-ray diffraction pattern is shown in Fig. 2. The prominent peaks in the powder X-ray diffraction confirm the crystalline nature of the grown crystal.

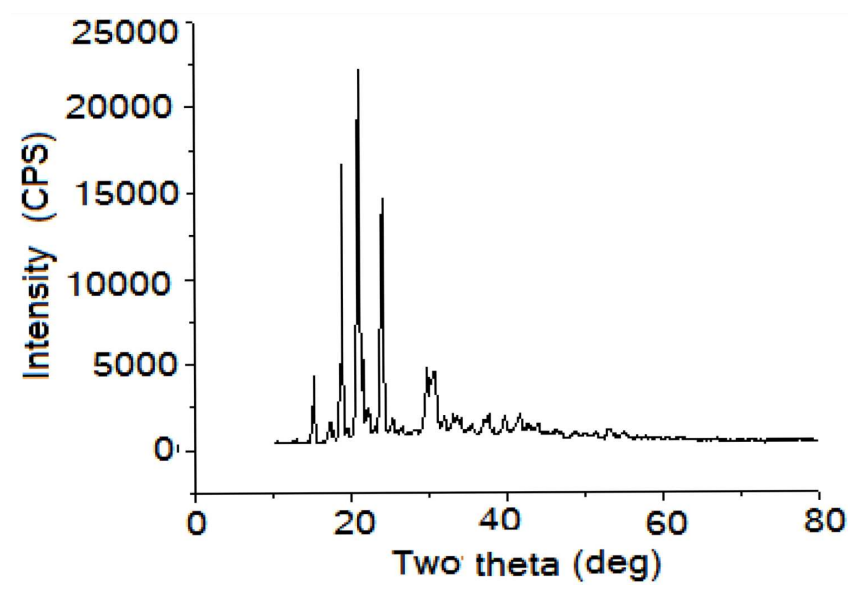

Fig. 2. Powder X-ray diffraction pattern of the LHAA.

\subsection{FT-IR spectral analysis}

The Fourier transform infrared (FT-IR) spectroscopy study is effectively used to identify the functional groups presents in the crystal. The FT-IR spectral analysis for the grown crystal has been recorded by using Perkin Elmer Spectrum one FT-IR spectrometer in the region 4000-400 $\mathrm{cm}^{-1}$ using $\mathrm{KBr}$ pellet technique with a resolution of $4 \mathrm{~cm}^{-1}$. The band intensities are expressed in transmittance (\%). Figure 3 depicts the FT-IR spectrum of grown crystal. The peak at $3003 \mathrm{~cm}^{-1}$ could be attributed to the $\mathrm{CH}$ stretching vibration. The peak at $2858 \mathrm{~cm}^{-1}$ is assigned to $\mathrm{CH}_{2}$ stretching vibration. The peak at $2708 \mathrm{~cm}^{-1}$ is assigned to $\mathrm{O}-\mathrm{H}$ stretching vibration. It is clearly seen that the existence of carboxylic acids $(\mathrm{COOH})$ functional groups. The fact that some of the $\mathrm{COOH}$ groups are ionized implicates an appearance of the $\mathrm{NH}_{3}^{+}$group in histidine molecule. The strong band at $1629 \mathrm{~cm}^{-1}$ in the infrared spectrum is attributed to $\mathrm{N}-\mathrm{H}$ bending vibration of $\mathrm{NH}_{3}^{+}$group. The peak at $1411 \mathrm{~cm}^{-1}$ is assigned to $\mathrm{C}-\mathrm{N}$ stretching (in-ring). The strong band at $1568 \mathrm{~cm}^{-1}$ in the infrared spectrum is attributed to asymmetric $\mathrm{NH}_{3}^{+}$group vibration. This peak is observed at $1577 \mathrm{~cm}^{-1}$ in histidine [3]. The peak at $1411 \mathrm{~cm}^{-1}$ is assigned to $\mathrm{C}-\mathrm{C}$ stretching (in-ring). The peak at $1340 \mathrm{~cm}^{-1}$ is assigned to $\mathrm{CH}_{2}$ scissoring vibration. The $\mathrm{C}-\mathrm{H}$ wagging vibration is assigned for the peak at $1247 \mathrm{~cm}^{-1}$ which indicates the alkyl halide stretching vibration $[4,5]$.

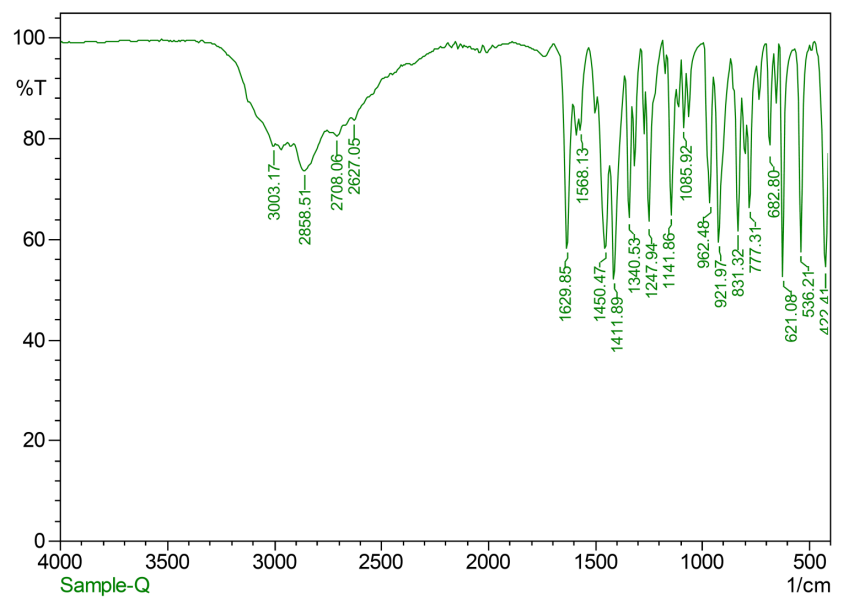

Fig. 3. FT-IR spectrum of LHAA crystal.

\subsection{FT-Raman spectral analysis}

The FT-Raman spectroscopic analysis is effectively used to determine the molecular structure and the identification of the functional groups in the synthesized compound. The FT-Raman spectra of the grown crystal were recorded in the range 50-4000 $\mathrm{cm}^{-1}$, using Bruker: RFS 27 FT-Raman spectrometer and shown in Fig. 4.

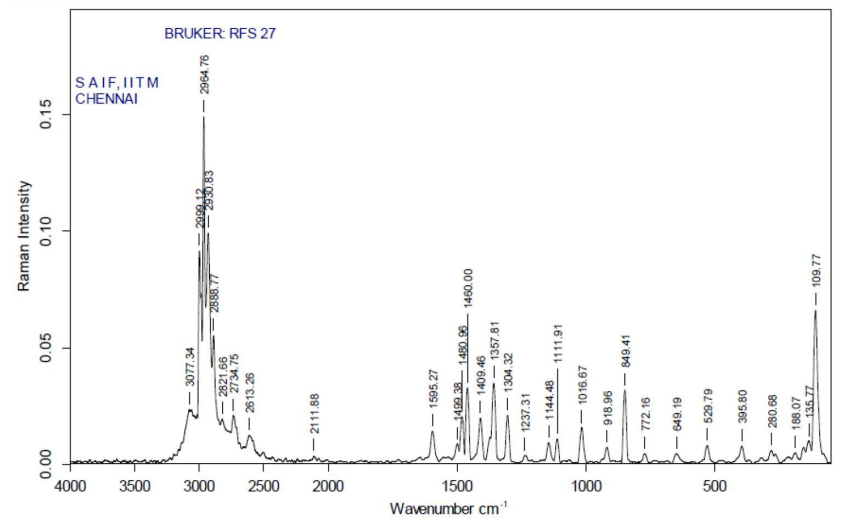

Fig. 4. Raman spectrum of LHAA crystal. 
Vibration band assignment of LHAA

TABLE I

\begin{tabular}{c|c|l}
\hline \hline \multicolumn{2}{c|}{ Wave number $\left[\mathrm{cm}^{-1}\right]$} & \multicolumn{1}{c}{ Assignment description } \\
\hline FT-IR $\left[\mathrm{cm}^{-1}\right]$ & FT-Raman $\left[\mathrm{cm}^{-1}\right]$ & \\
\hline- & 3077 & $\mathrm{O}-\mathrm{H}$ stretching \\
3003,2858 & $2999,2930,2888$ & $\mathrm{C}-\mathrm{H}$ stretching \\
2708 & - & $\mathrm{O}-\mathrm{H}$ stretching \\
1629 & - & $\mathrm{N}-\mathrm{H}$ bending of $\mathrm{NH}_{3}^{+}$group. \\
1568 & 1595 & $\mathrm{NH}_{3}$ asymmetric stretching \\
1450 & 1460 & $\mathrm{C}-\mathrm{N}$ stretching mixed with $\mathrm{C}-\mathrm{C}$ stretching \\
1411 & 1409 & $\mathrm{C}-\mathrm{N}$ stretching (in-ring) \\
- & 1499,1409 & $\mathrm{C}-\mathrm{H}$ wagging $\left(-\mathrm{CH}_{2} \mathrm{X}\right)$ \\
1340 & 1357 & $\mathrm{CH} \mathrm{H}_{2}$ scissoring vibration \\
1247 & 1237 & $\mathrm{C}-\mathrm{H}$ wagging $(-\mathrm{CH}$ X) \\
1141 & 1144 & $\mathrm{CH}$ twist modes with mixing of $\mathrm{CH}$ and $\mathrm{NH}$ bending \\
- & 1111 & $\mathrm{CH}_{3}$ rocking \\
962 & 918 & $\mathrm{NH}_{3}$ rocking $+\mathrm{CH}_{\text {bending }}$ \\
921 & 649 & $\mathrm{C}-\mathrm{N}$ stretching $+\mathrm{NH}$ bending $+\mathrm{C}-\mathrm{C}$ stretching \\
621 & 529 & $\mathrm{COO}$ deformation \\
536 & $188,135,109$ & $\mathrm{Ring}$ deformation $+\mathrm{CN}$ bending \\
- & Lattice vibrations in crystals
\end{tabular}

In the FT-Raman spectra, peaks around $3077 \mathrm{~cm}^{-1}$ are assigned to $\mathrm{O}-\mathrm{H}$ stretching vibration. Sharp peaks at $2999 \mathrm{~cm}^{-1}, 2930 \mathrm{~cm}^{-1}$, and $2888 \mathrm{~cm}^{-1}$ are assigned to $\mathrm{C}-\mathrm{H}$ symmetric stretching vibration. The peak observed at $1595 \mathrm{~cm}^{-1}$ is assigned to $\mathrm{NH}_{3}$ asymmetric vibration. The peak at $1409 \mathrm{~cm}^{-1}$ is assigned to $\mathrm{C}-\mathrm{H}$ wagging $\left(-\mathrm{CH}_{2} \mathrm{X}\right)$ which indicates alkyl halides. The peak at $1357 \mathrm{~cm}^{-1}$ is assigned to $\mathrm{CH}_{2}$ scissoring vibration. The peak at $1111 \mathrm{~cm}^{-1}$ is attributed to $\mathrm{CH}_{3}$ rocking vibration, and the peak at $918 \mathrm{~cm}^{-1}$ is attributed to mixed vibration of $\mathrm{C}-\mathrm{N}$ stretching and $\mathrm{NH}$ bending. These two stretching vibration indicates carboxylic acids functional group present in the substance. The strong and sharp peaks at $188 \mathrm{~cm}^{-1}, 135 \mathrm{~cm}^{-1}$, and $109 \mathrm{~cm}^{-1}$ are assigned to lattice vibrations in crystals $[4,5]$. The other observed peaks in the spectrum of FT-IR and the FTRaman are assigned to their corresponding bands and functional groups and are tabulated in Table I.

\subsection{Ultraviolet-visible spectroscopic studies}

The ultraviolet-visible spectrum analysis of the grown crystal was carried out in the wavelength range of 200-800 $\mathrm{nm}$. The recorded absorption spectrum is shown in Fig. 5. The cut-off wavelength of LHAA crystal has been identified as $208 \mathrm{~nm}$. It is observed that the wide range of optical transmission window occurs from 208 to $800 \mathrm{~nm}$. There is no considerable absorption of light in the visible range of an electromagnetic spectrum which is an internal property of amino acids. Hence they can be used for fabrication of optical region. The optical band energy gap for a grown crystal was calculated using the Tauc equation $\alpha h \nu=A\left(h \nu-E_{g}\right)^{n}$ where $\alpha$ is the absorption coefficient, $h$ is the Planck constant, $\nu$ is the frequency of incident photons, and $A$ is a constant. The linear portion of the plot of $(\alpha h \nu)^{2}$ versus $h \nu$, when

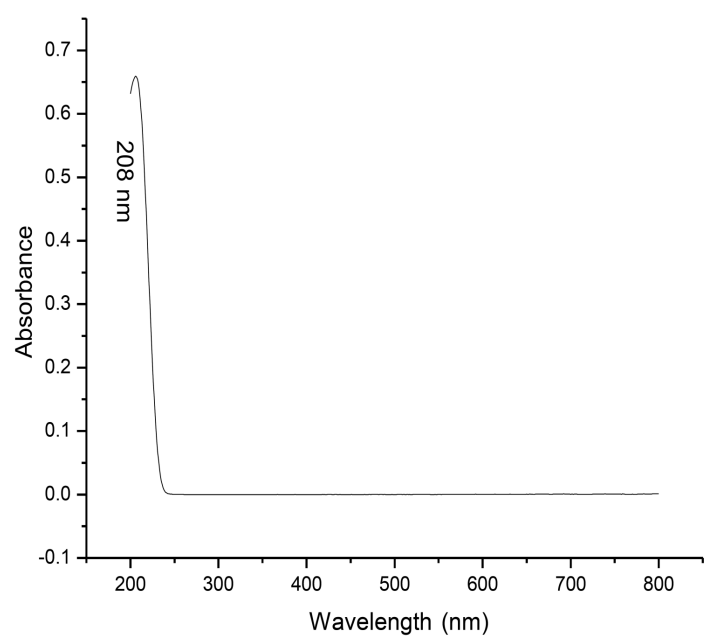

Fig. 5. UV-visible spectrum of LHAA crystal.

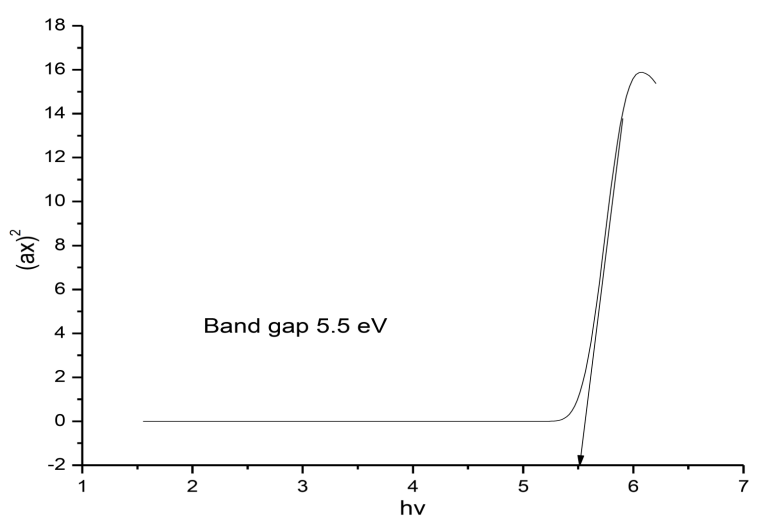

Fig. 6. Band gap of LHAA crystal. 
extrapolated to the energy axis, gives the band energy gap. A plot of $(\alpha h \nu)^{2}$ versus $h \nu$ is shown in Fig. 6. From the intercept of straight line on the energy axis, the band gap was found to be $5.5 \mathrm{eV}$. Large value of band gap indicates that the material is a good insulator and can provide large transmission in visible region [6-11].

\subsection{Thermal analysis}

In order to study the thermal stability of the grown crystal, thermogravimetric analysis (TGA) have been carried out using a SDT Q600 V20.9 Build 20 model thermal analyser in an inert nitrogen atmosphere. Powdered sample of about $3.6810 \mathrm{mg}$ was used for the analysis in the temperature range of $28-800^{\circ} \mathrm{C}$ with a heating rate of $20^{\circ} \mathrm{C} / \mathrm{min}$. The TGA and differential scanning calorimetry (DSC) pattern recorded for the grown crystal LHAA as shown in Figs. 7 and 8, respectively. The TGA trace shows that there is no weight loss below $286.6^{\circ} \mathrm{C}$, hence the crystal is completely devoid of any entrapped solvent in the lattice of the crystal. The major weight loss occurs at three stages. First stage of weight loss of about $15.94 \%$ $(0.4831 \mathrm{mg})$ is observed between $255.5^{\circ} \mathrm{C}$ and $286.6^{\circ} \mathrm{C}$ which is due to the decomposition of L-histidine. Second stage of weight loss of about $25.12 \%$ (0.767 mg), observed between $286.6^{\circ} \mathrm{C}$ to $390.5^{\circ} \mathrm{C}$, is due to step by step decomposition and release of volatile substances in the compound, probably ammonia and carbon dioxide. The third stage gradual weight loss of about $20.12 \%$ (0.646 mg) observed for wider range of temperature between $390.5^{\circ} \mathrm{C}$ to $800^{\circ} \mathrm{C}$ is due to the decomposition of ammonium acetate. These three different stages of weight loss indicate the decomposition of the substance. The final residue weight left was $38.94 \%$ (1.189 mg) was found after heating to $800^{\circ} \mathrm{C}$. The DSC analysis of the grown crystal was carried out between $28^{\circ} \mathrm{C}$ and $800^{\circ} \mathrm{C}$. There is a sharp endothermic peak starting from $273.02^{\circ} \mathrm{C}$ to $291.38^{\circ} \mathrm{C}$, which corresponds to the decomposition as observed in TGA analysis. Again it also confirms absence of melting and any entrapped solvent in the lattice. DSC curve shows the sharp endothermic peak that indicates that the crystal has good crystallinity and decomposition point of as grown LHAA crystal is $291.38^{\circ} \mathrm{C}$. The TGA-DSC result shows that the grown crystal is thermally stable up to $273.02^{\circ} \mathrm{C}$ and establishes its suitability to withstand the high temperature for laser experiment carried out between $28^{\circ} \mathrm{C}$ and $800^{\circ} \mathrm{C}[9-13]$.

\subsection{Second harmonic generation studies}

In order to confirm the nonlinear optical property, powdered sample of LHAA was subjected to a Kurtz and Perry powder techniques, which remains as a powerful tool for initial screening of materials for SHG. A Q switched high energy Nd:YAG laser (QUANTA RAY Model LAB - 170-10) operating at the fundamental wavelength of $1064 \mathrm{~nm}$ with pulse width $8 \mathrm{~ns}$ and repetition rate of $10 \mathrm{~Hz}$ and input energy as $0.701 \mathrm{~J}$ was used. The NLO property of the sample was confirmed by the emission of bright green light with $2.903 \mathrm{~mJ} /$ pulse as

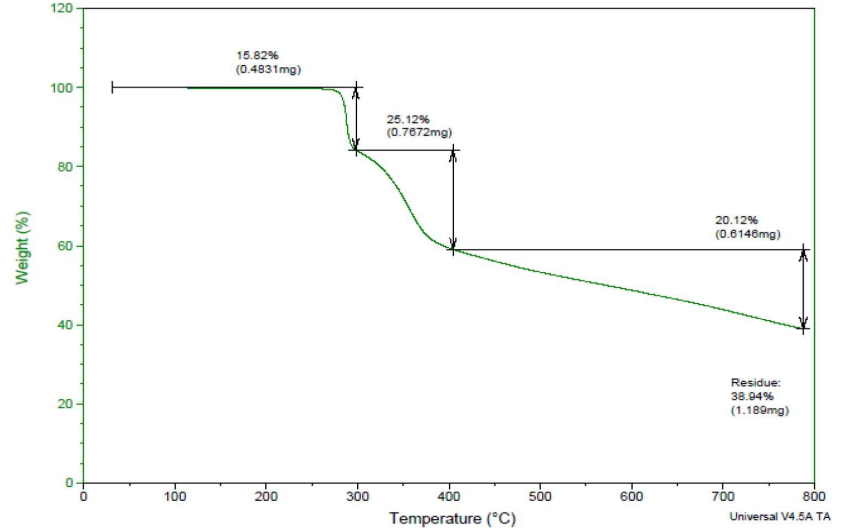

Fig. 7. TGA curves of LHAA crystal.

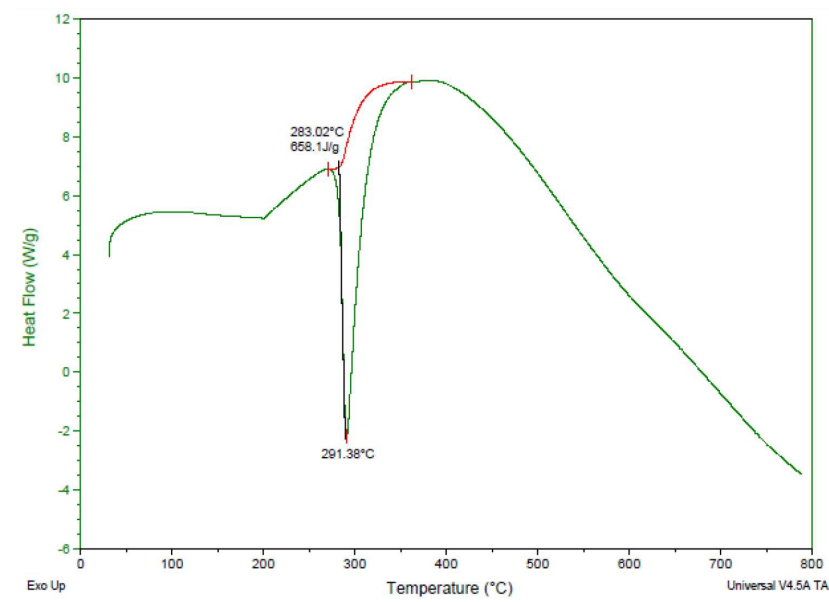

Fig. 8. DSC curves of LHAA crystal.

output with wavelength of $532 \mathrm{~nm}$. The KDP sample was used as the reference material which gives a signal $9.0701 \mathrm{~mJ} /$ pulse for the same input energy. The efficiency of second harmonic generation of L-histidine ammonium acetate crystal was found to be 0.68 times lesser that of the reference material KDP. Thus LHAA crystal can be used as an effective candidate for nonlinear optical applications [14-18].

\section{Conclusion}

An organic nonlinear optical crystal of LHAA has been successfully grown from aqueous solution by slow evaporation technique at the room temperature. The crystalline nature of the grown crystal has been confirmed by powder X-ray diffraction. The single crystal $\mathrm{X}$-ray diffraction study shows that the grown crystal belongs to monoclinic system with space group of $P 2_{1} 2_{1} 2_{1}$. The different functional groups presented in the grown crystal have been identified by the Fourier transform infrared and Raman spectroscopy (FTIR). The UVvisible spectroscopic studies showed that the grown crystal was optically transparent in the entire visible region 
and the cut-off wavelength has been identified as $208 \mathrm{~nm}$. Hence they can be used for fabrication of optoelectronic devices in visible region. The optical band energy gap $\left(E_{g}\right)$ was found to be $5.5 \mathrm{eV}$ from the Tauc relation. The TGA and DSC shows that the grown crystal is thermally stable up to $273.02{ }^{\circ} \mathrm{C}$ and establishes its suitability to withstand the high temperature for laser experiments. The SHG efficiency of the grown crystal was measured by the Kurtz and Perry powder techniques and its efficiency was found to be 0.68 times lesser than that of the reference material KDP. Thus LHAA crystal can be used as an effective candidate for non-linear optical applications.

\section{References}

[1] P. SanthanaRagavan, P. Ramasamy, Crystal Growth Processes and Methods, KRU Publ., Kumbakonam 2003.

[2] S.L. Gupta, V. Kumar, Solid State Physics, K. Nath and Co., Educational Publ., Meerut (India) 2018.

[3] S. Kumar, A.K. Rai, S.B. Rai, D.K. Rai, Indian J. Phys. 84, 563 (2010).

[4] R.M. Silverstein, G. Clayton Basseler, T.C. Morrill, Spectrometric Identification of Organic Compounds, 5th ed., Wiley, New York 1998.

[5] P.S. Kalsi, Spectroscopic of Organic Compounds, New Age International (P) Ltd., New Delhi 2002.

[6] S.K. Kurtz, T.T. Perry, J. Appl. Phys. 39, 3798 (1968).
[7] R.L. Sutherland, Handbook of Nonlinear Optics, 2nd ed., New York 2003.

[8] D.S. Chemla, J. Zyss, Nonlinear Optical Properties of Organic Molecules and Crystals, Academic Press, New York 1987.

[9] S.E. Joema, S. Perumal, S. Ramalingam, P. Selvarajan, Recent Res. Sci. Technol. 3, 63 (2011).

[10] J. Mahadevan, S. Aruna, A. Anuradha, D. Premanand, I. VethaPotheher, K. Thamizharasan, P. Sagayaraj, Opt. Mater. 29, 1211 (2007).

[11] P. Anandan, R. Jayavel, J. Cryst. Growth 322, 69 (2011).

[12] S.A. Martin Britto Dhas, S. Natarajan, Opt. Commun. 281, 457 (2008).

[13] A.B. Ahmed, H. Feki, Y. Abid, H. Boughzala, A. Mlayah, J. Mol. Struct. 888, 180 (2008).

[14] J. Chandrasekaran, P. Ilayabarathi, P. Maadeswaran, P. Mohamed Kutty, S. Pari, Opt. Commun. 285, 2096 (2012).

[15] M.R. Ramanan, R. Radhakrishnan, S. Krishnan, V. Chithambaram, Int. J. Sci. Eng. Technol. 2, 485 (2013).

[16] R. Ittyachan, P. Sagayaraj, J. Cryst. Growth 249, 557 (2003).

[17] P. Anandan, R. Jayavel, J. Cryst. Growth 322, 69 (2011).

[18] V. Rajendran, D. Shyamala, M. Loganayaki, P. Ramasamy, Mater. Lett. 61, 3477 (2007). 